\title{
Specific and non-specific binding of a tracer for the translocator-specific protein in schizophrenia: an [11C]-PBR28 blocking study
}

\author{
Tiago Reis Marques ${ }^{1,2,3}$ (D) Mattia Veronese ${ }^{4}$ David R. Owen ${ }^{5}$. Eugenii A. Rabiner ${ }^{4,6} \cdot$ Graham E. Searle $^{6}$. \\ Oliver D. Howes ${ }^{1,2,3}$
}

Received: 24 August 2020 / Accepted: 21 March 2021 / Published online: 6 April 2021

(C) The Author(s) 2021

\begin{abstract}
Objective The mitochondrial $18-\mathrm{kDa}$ translocator protein (TSPO) is expressed by activated microglia and positron emission tomography enables the measurement of TSPO levels in the brain. Findings in schizophrenia have shown to vary depending on the outcome measure used and this discrepancy in TSPO results could be explained by lower non-displaceable binding $\left(V_{\mathrm{ND}}\right)$ in schizophrenia, which could obscure increases in specific binding. In this study, we have used the TSPO ligand XBD173 to block the TSPO radioligand $\left[{ }^{11} \mathrm{C}\right]$-PBR28 and used an occupancy plot to quantify $V_{\mathrm{ND}}$ in patients with schizophrenia.

Methods A total of 7 patients with a diagnosis of schizophrenia were recruited for this study. Each patient received two separate PET scans with $\left[{ }^{11} \mathrm{C}\right] \mathrm{PBR} 28$, one at baseline and one after the administration of the TSPO ligand XBD173. All patients were high-affinity binders (HABs) for the TSPO gene. We used an occupancy plot to quantify the non-displaceable component $\left(V_{\mathrm{ND}}\right)$ using $2 \mathrm{TCM}$ kinetic estimates with and without vascular correction. Finally we computed the $V_{\mathrm{ND}}$ at a single subject level using the SIME method. Results All patients showed a global and generalized reduction in $\left[{ }^{11} \mathrm{C}\right] \mathrm{PBR} 28$ uptake after the administration of XBD173. Constraining the $V_{\mathrm{ND}}$ to be equal for all patients, the population $V_{\mathrm{ND}}$ was estimated to be $1.99 \mathrm{~mL} / \mathrm{cm}^{3}$ (95\% CI 1.90 to 2.08 ). When we used vascular correction, the fractional TSPO occupancy remained similar.

Conclusions In schizophrenia patients, a substantial component of the $\left[{ }^{11} \mathrm{C}\right] \mathrm{PBR} 28$ signal represents specific binding to TSPO. Furthermore, the $V_{\mathrm{ND}}$ in patients with schizophrenia is similar to that previously reported in healthy controls. These results suggest that changes in non-specific binding between schizophrenia patients and healthy controls do not account for discrepant PET findings in this disorder.
\end{abstract}

Keywords TSPO $\cdot$ Schizophrenia $\cdot$ Microglia $\cdot$ XBD173

This article is part of the Topical Collection on Infection and inflammation

Tiago Reis Marques

t.dos-reis-marques@1ms.mrc.ac.uk

1 Psychiatric Imaging Group, MRC London Institute of Medical Sciences (LMS), Hammersmith Hospital, Imperial College London, London, UK

2 Psychiatric Imaging Group, Institute of Clinical Sciences (ICS), Faculty of Medicine, Imperial College London, London, UK

3 Department of Psychosis Studies, Institute of Psychiatry, Psychology and Neuroscience, Kings College London, London, UK

4 Centre for Neuroimaging Sciences, Institute of Psychiatry, King's College London, London, UK

5 Division of Brain Sciences, Department of Medicine, Imperial College, London, UK

6 Invicro, London, UK

\section{Introduction}

Schizophrenia is the result of a complex interplay between multiple pathophysiological mechanisms [18]. Recent studies have produced converging evidence supporting a role of inflammation and immune response as an important contributor to the pathogenesis of this disorder [17]. In the central nervous system, microglia cells play a key role in the response to an inflammatory stimulus, changing from a quiescent (resting) state to an activated state and releasing pro-inflammatory cytokines. When microglia are activated, they increase the expression of the mitochondrial 18-kDa translocator protein (TSPO) [6]. By using radioligands targeting this protein, positron emission tomography (PET) enables the measurement of TSPO levels in the brain. Multiple studies have used PET tracers for TSPO to investigate this marker in schizophrenia-spectrum disorders $([2,4,11,15,41,10,16,37,5,9,29,32,40,41])$. However, findings have varied depending on the outcome 
measure used, with a recent meta-analysis showing that TSPO PET tracer binding is significantly elevated in patients with schizophrenia relative to controls when binding potential (BP) is used as an outcome measure, but when the tracer volume of distribution $\left(V_{\mathrm{T}}\right)$ is used as the outcome measure, no significant differences are seen between patients with schizophrenia and healthy controls [26]. Binding potential uses a reference region to account for binding of the tracer to other brain constiuents other than TSPO, often termed non-displaceable binding, while $V_{\mathrm{T}}$ represents both specific binding to TSPO and nondisplaceable binding by the tracer [20]. Non-specific binding refers to the radioligand non-specifically bound to molecules other than the target of interest and free radioligand in the tissue ([20]; Rosso et al., 2008; Ogden et al., 2014). Thus, the discrepant TSPO results could be explained by lower nondisplaceable binding in schizophrenia, which could obscure increases in specific binding, accounting for the lack of differences reported in many of the studies, and a small decrease in $V_{\mathrm{T}}$ on a pooled analysis [32]. However, it is not known if nondisplaceable binding is altered in schizophrenia. Nondisplaceable binding $\left(V_{\mathrm{ND}}\right)$ can be estimated through pharmacological blockade using a drug that blocks tracer binding to the protein of interest. Importantly, this approach is considered the "gold standard" for the in vivo estimatation of $V_{\mathrm{ND}}$. A previous study in healthy controls used a drug that selectively binds to the TSPO (XBD173) to block the specific binding signal of $\left[{ }^{11} \mathrm{C}\right] \mathrm{PBR} 28$ and calculate the $V_{\mathrm{ND}}$ [31]. By using an occupancy plot, the $V_{\mathrm{ND}}$ at a population level was calculated as being $1.98 \mathrm{~mL} / \mathrm{cm}^{3}$. Finally, a recent study used the same method to calculate the $V_{\mathrm{ND}}$ of [11C]PBR28 in multiple sclerosis as being $3.81 \mathrm{~mL} / \mathrm{cm}^{3}$, which suggests $V_{\mathrm{ND}}$ may be altered in pathological states (Sridharan et al., 2019). As $V_{\mathrm{ND}}$ is unknown in schizophrenia, we performed a PET imaging study using pharmacological blockage with XBD173 to calculate, for the first time, the $V_{\mathrm{ND}}$ in patients with schizophrenia.

\section{Material and methods}

\section{Participants and experimental protocol}

The study protocol was approved by the National Research Ethics Service (NRES) and permission to administer radioactive substances was granted by the Administration of Radioactive Substances Advisory Committee (ARSCAC), UK. All participants gave written informed consent to participate after receiving a full description of the study. In total, seven patients with a diagnosis of schizophrenia were recruited from the South London and Maudsley Foundation NHS Trust. Out of the 7 participants, baseline, but not blocking data, were included from 6 in a previous report (Bloomfiled et al., 2016). Diagnosis was ascertained through clinical interview and reviewing medical records, and all patients met DSM-5 criteria for schizophrenia according to the Structured Clinical Interview of DSM-5-TR Axis I Disorders (SCID). Subjects were then screened based on the following exclusion criteria: exposure to any medication except antipsychotics, including anti-inflammatory and benzodiazepine medications, in the last month; history of substance abuse/dependence as determined by the Structured Clinical Interview of DSM-5-TR Axis I Disorders (SCID) [13]; history of head injury resulting in unconsciousness, or any physical medical condition associated with inflammation; low-affinity binder for the TSPO gene; significant prior exposure to radiation; pregnancy or breast feeding. Patients were genotyped for the TSPO genetic polymorphism and all subjects were high affinity binders (HABs) for this polymorphism.

Each patient received two separate PET scans with $\left[{ }^{11} \mathrm{C}\right] \mathrm{PBR} 28$, one at baseline and one after XBD173 administration. As circadian rhythms may impact TSPO measurement $[3,7]$, PET scans were conducted at similar time of the day (mean injection time: 14:32; earliest injection: 10:46; latest injection: 15:56) in order to reduce intra and inter-subject variability. At the time of PET scanning, all patients were stabilized on antipsychotic treatment. At both baseline and followup visits, subjects had a physical, psychiatric, and neurological examination and no participant had a history of other neurological or psychiatric disorders other than schizophrenia. Clinical measures were recorded at both PET scans, including physical examination and medication history. Drug screens were done on the days of the scans to exclude the use of psychoactive drugs. Psychotic symptoms were evaluated using the Positive and Negative Syndrome Scale (PANSS) [21].

\section{XBD173 (emapunil) administration}

$\mathrm{XBD} 173$ is a selective TSPO agonist, binding to this site with nanomolar affinity [31]. All seven participants received a standard oral dose of $90 \mathrm{mg}$ of XBD173 corresponding to $0.98 \pm$ $0.16 \mathrm{mg} / \mathrm{kg}$ (mean $\pm \mathrm{SD}$ ) based on the patient weights. This dose has been previously tested in healthy controls and was shown to be safe, well tolerated with no reported side effects [31]. This dose aimed to reach between 66 and $77 \%$ of TSPO brain occupancy and was given $2 \mathrm{~h}$ prior to radiotracer injection, which was timed to coincide with the anticipated peak concentration of XBD173 in blood [31].

\section{Neuroimaging evaluation}

\section{Image acquisition}

Participants were instructed to refrain from caffeine, tobacco, and alcohol for at least $12 \mathrm{~h}$ before scanning. All participants were scanned twice on a Siemens Biograph TruePoint PET/CT 
scanner (Erlangen, Germany) following the injection of an intravenous bolus $\left[{ }^{11} \mathrm{C}\right]$ PBR28. Dynamic emission data were acquired continuously for $90 \mathrm{~min}$ following the injection of $\left[{ }^{11} \mathrm{C}\right]$ PBR28. PET data were acquired in three-dimensional mode and binned into 26 frames (durations: $8 \times 15 \mathrm{~s}, 3 \times$ $1 \mathrm{~min}, 5 \times 2 \mathrm{~min}, 5 \times 5 \mathrm{~min}, 5 \times 10 \mathrm{~min}$ ). Images were reconstructed using filtered back projection and corrected for attenuation and scatter. During PET acquisition, arterial blood data were collected via the radial artery using a combined automatic-manual approach. A continuous sampling system (ABSS Allogg, Mariefred, Sweden) was employed to measure whole blood activity for first 15 min of each scan at the rate of one sample per second. Discrete blood samples were manually withdrawn at $5,10,15,20,25,30,40,50,60,70,80$, and $90 \mathrm{~min}$, centrifuged, and used to determine the plasma over blood activity ratio (POB). Samples at 5, 10, and 15 min were used to calibrate the two sampling modalities. Samples taken at $5,10,20,30,50,70$, and 90 min were also analyzed using HPLC to calculate the plasma fraction of tracer free of metabolites (PPf). Radiometabolite analysis of $\left[{ }^{11} \mathrm{C}\right] \mathrm{PBR} 28$ blood data was done as described by Owen et al. [31], consistent with previous studies [2]. Parent plasma fraction (PPf) and plasma over blood (POB) were fitted with an extended Hill model [12]. Whole blood TACs were fitted using a multi-exponential model [39]. For each scan, a time delay was fitted and applied to the input functions (both parent and whole blood TACs) to account for temporal delay between blood sample measurement and the target tissue data. MRI scans were acquired with a 32-channel head coil on a Siemens Magnetom Verio, 3-T MRI scanner and included a T1-weighted magnetization prepared rapid gradient echo sequence (MPRAGE; time repetition $(\mathrm{TR})=2300 \mathrm{~ms}$, time echo $(\mathrm{TE})=2.98 \mathrm{~ms}$, flip angle of $9^{\circ}$, time to inversion $(\mathrm{TI})=900 \mathrm{~ms}$, matrix $=240 \times 256)$ for co-registration with the PET images. All sequences used a $1 \mathrm{~mm}^{3}$ voxel size, anteroposterior phase encoding direction, and a symmetric echo.

\section{$\left[{ }^{11} \mathrm{C}\right]$ PBR28 PET data processing}

\section{Data analysis}

Each subject's structural MRI image underwent brain extraction and gray matter segmentation using Statistical Parametric Mapping (SPM) 8 (http://www.fil.ion.ucl.ac.uk/spm). A neuroanatomical atlas (CIC atlas 2.0) was co-registered to each subject's MRI scan and PET image using a combination of SPM 8 and FSL (http://www.fsl.fmrib.ox.ac.uk/fsl) functions, implemented in the MIAKAT ${ }^{\mathrm{TM}}$ software package (http://www.imanova.co.uk).

Region of interest (ROI) definition included the occipital lobe, temporal lobe, frontal lobe, parietal lobe, insular cortex, cingulate cortex, amygdala, hippocampus, thalamus, striatum, and cerebellum. Whole brain and gray and white matter were also included in analysis. Dynamic PET images were linearly registered to each subject's MRI scan and corrected for subject motion using non-attenuation-corrected images, as they include greater scalp signal, which improves re-alignment compared to attenuation-corrected images. Frames were realigned to a single "reference" space identified by the PET frame with the highest activity. The transformation parameters were then applied to the corresponding attenuation-corrected PET frames, creating a movement-corrected dynamic image for analysis. ROIs were applied to the dynamic PET data to derive regional time-activity curves (TACs). To investigate the effect of XBD173 on $\left[{ }^{11} \mathrm{C}\right] \mathrm{PBR} 28$ tissue uptake, standardized uptake values (SUV), using injected dose and patient weight as normalization factors, were computed $90 \mathrm{~min}$ after tracer injection for each PET scan.

\section{Kinetic modeling}

For consistency with previous blocking studies with TSPO PET tracers $[19,22,31]$, quantification of $\left[{ }^{11} \mathrm{C}\right] \mathrm{PBR} 28$ tissue distribution was performed using a standard 2TCM, using the metabolite corrected plasma input function. The 2TCM model was solved using the weighted non-linear least square estimator (WNLLS), as implemented in Matlab2012b (The Mathworks Inc., Natick, MA). The total distribution volume $\left(V_{\mathrm{T}}\right)$ was then determined for each one of the ROI examined. Regions with $V_{\mathrm{T}}$ estimates higher than $10 \mathrm{~mL} / \mathrm{cm}^{3}$ or with unreliable precision ( $\mathrm{CV}>50 \%)$ were excluded from the analysis as non-physiological based on previous analysis [34]. In addition, we have tested the $2 \mathrm{TCM} 1 \mathrm{~K}$ model to test whether the inclusion of a vascular compartment would predict a different percentage of specific binding than standard 2TCM. Finally, we compute the $V_{\mathrm{ND}}$ at a single subject levels using the SIME method [38].

\section{Quantification of the non-displaceable component $\left(V_{\mathrm{ND}}\right)$}

The occupancy plot [8], a revisited version of the original Lassen plot for the calculation of the fractional receptor availability in molecular imaging studies [24], assumes that the $V_{\mathrm{ND}}$ of the radioligand is unchanged by the administration of the blocking drug, and that the fractional occupancy of the target by the blocking drug is the same across all ROI. With these assumptions, it follows that:

$$
\begin{aligned}
V_{\mathrm{T}} \text { Baseline }-V_{\mathrm{T}} \text { Blocking }= & \text { Occupancy } \\
& \times\left(V_{\mathrm{T}} \text { Baseline }-V_{\mathrm{ND}}\right)
\end{aligned}
$$

Therefore, by plotting ( $V_{\mathrm{T}}$ Baseline - $V_{\mathrm{T}}$ Blocking) versus $V_{\mathrm{T}}$ Baseline, it is possible to obtain a measure of both target occupancy (the slope) and the $V_{\mathrm{ND}}$ (the $x$-intercept). Baseline and post-XBD173 $V_{\mathrm{T}}$ data for each one of the ROI in each of 
subjects were fitted to the occupancy plot. $V_{\mathrm{ND}}$ values were then calculated individually for each subject. Consistent with previous literature ([31]; Sridharan et al., 2019), to increase noise robustness, all subjects were constrained to the same $V_{\mathrm{ND}}$ value. This approach allowed us to compare differences in $V_{\mathrm{ND}}$ between healthy population and a clinical one.

\section{Implementation SIME method}

The SIME method requires to define a priori a grid of possible $V_{\mathrm{ND}}$ values. Then, for each element of the grid, a $2 \mathrm{TCM}$ is fitted to all TACs by constraining $K_{1} / k_{2}$ to be equal to chosen $V_{\mathrm{ND}}$ value in all the ROIs. The residual sum of squares is then computed for all ROIs and frames, and the $V_{\mathrm{ND}}$ value that yields the lowest residual sum of squares is selected as the estimate of a brain-wide $V_{\mathrm{ND}}$.

SIME method was implemented consistently with previous applications of the method to 11C-PBR28 PET imaging ([33]; Schain et al., 2019), by using public available code (https:// github.com/martinschain/SIME). Only baseline PET scans were considered. The $V_{\mathrm{ND}}$ grid was selected from 0.01 to 5 , with steps of 0.01 . Weights and ROIs were kept consistent with the kinetic modeling and occupancy plot analysis.

\section{Statistical analysis}

Statistical analyses were conducted in SPSS version 19 (www.spss.com). Paired $t$-tests as well as repeated measured ANOVAs (rmANOVA) were used to assess differences between $\left[{ }^{11} \mathrm{C}\right]$ PBR28 PET scans at baseline and after XBD173 administration.

\section{Results}

\section{Demographic and clinical characteristics of study participants}

A total of 7 patients with schizophrenia were included in this study. All patients were male, the mean age of participants at the time of baseline scan was $41.8 \pm 14.3$ years, and the interval between scans was 743.2 \pm 335.2 days. At the time of PET scanning, 6 patients were stabilized and receiving treatment with standard antipsychotics while one patient was unmedicated. Between baseline and follow-up scan, there were minimal changes in antipsychotic medications in 4 patients out of 7 , while in two cases, the antipsychotic treatment was changed: case 1 from Amisulpride $200 \mathrm{mg}$ /day to Olanzapine $10 \mathrm{mg}$ /day; case 2 from Olanzapine $10 \mathrm{mg}$ /day to Risperidone $3 \mathrm{mg} /$ day. One subject remained unmedicated at both PET scans (see Table 1).

There were no significant differences in the injected doses between baseline $\left[{ }^{11} \mathrm{C}\right]$ PBR2 8 scans (mean baseline radioactivity: $321 \pm 32(\mathrm{SD}) \mathrm{MBq}$ ) and follow-up XBD173 blocking scans (mean post-XBD173 radioactivity: $302 \pm 75$ (SD) $\mathrm{MBq},(p=0.58))$. There was no difference in injected mass $(p=0.36)$ at follow-up (mean post-XBD173 injected mass: $4.1 \pm 2.1$ (SD) $\mu \mathrm{g}$ ) when compared to baseline (mean baseline injected mass: $2.2 \pm 0.6$ (SD) $\mu \mathrm{g}$ ). Similarly, there was a lower $(p=0.23)$ specific activity at baseline (mean baseline-specific activity: $53.7 \pm 13.7$ (SD) $\mathrm{GBq} / \mu \mathrm{mol}$ ) when compared to follow-up (mean post-XBD173-specific activity: $32.7 \pm 14.6(\mathrm{SD}) \mathrm{GBq} / \mu \mathrm{mol})$. There were no reported side effects after the administration of XBD173.

\section{Estimation of non-displaceable volume of distribution}

There was a global and generalized reduction in $\left[{ }^{11} \mathrm{C}\right]$ PBR28 uptake after the administration of XBD173 in all subjects (Fig. 1). This reduction was observed in all ROIs analyzed including the cerebellum. Even when the tracer-specific activity was used as a covariate, these reductions remained significant $(p=0.02)$, with no interaction between specific activity and standard uptake value (SUV) $(p=0.97)$. The same pattern of global reduction was present in the $V_{\mathrm{T}}$ estimates for both standard 2TMC and 2TCM with vascular correction (Table 2) and was confirmed by parametric mapping analysis (Supplementary Material). With 2TCM, all the subjects displayed a measurable occupancy of the TSPO following blockade with XBD173 about $56 \% \pm 12 \%$ for whole brain, $\% 54 \pm 7 \%$ in white matter and $\% 53 \pm 18 \%$ in gray matter. Similarly, 2TCM1K kinetic analysis led to a fractional occupancy of the TSPO following blockade with XBD173 about $60 \% \pm 24 \%$ for whole brain, $\% 49 \pm 20 \%$ in white matter, and $\% 67 \pm 20 \%$ in gray matter. These percentage $V_{\mathrm{T}}$ variations were consistent between the two models (two-tail paired $t$-test $p>0.1)$ although the tracer uptake was differentially associated with different model compartments. For a full analysis of micro- and macro-parameters obtained with 2TCM and $2 \mathrm{TCM} 1 \mathrm{~K}$, we refer the interested reader to Veronese et al. [43].

The regional volumes $V_{\mathrm{T}}$ were then used in an occupancy plot to calculate the occupancies (occupancy) and nondisplaceable volume $\left(V_{\mathrm{ND}}\right)$. Individual $V_{\mathrm{ND}}$ values ranged from 1.50 to 5.55 with a group average of $2.59(N=7,95 \%$ CI: 1.58 to 3.59 ) and between subject variability of $49 \%$. One subject with very high baseline $V_{\mathrm{T}}$ values $(38 \% \pm 3 \%$ greater than the average of the remaining 6 subjects) was mainly responsible for this high variability. When this subject was removed from the analysis, the $V_{\mathrm{ND}}$ group average was 2.17 $(N=6,95 \%$ CI: 1.67 to 2.66$)$ and the between subject variability was $29 \%$. Constraining the $V_{\mathrm{ND}}$ to be equal for all patients (no outlier removed), the population $V_{\mathrm{ND}}$ was estimated to be $1.99 \mathrm{~mL} / \mathrm{cm}^{3}$ ( $N=7,95 \%$ CI: 1.90 to 2.08$)$ with occupancy of $97 \% \pm 22 \%$ (Fig. 2 A).

When we used $2 \mathrm{TCM} 1 \mathrm{~K}$ individual $V_{\mathrm{ND}}$ estimates calculated with the occupancy plot ranged from 0.14 to 1.03 with a 
Table 1 Summary of participant demographics, medication, and radioactivity status at baseline and after XBD173 administration

\begin{tabular}{llll}
\hline Participant & $\begin{array}{l}\text { Interval between } \\
\text { scans (days) }\end{array}$ & Antipsychotic medication & \\
\cline { 3 - 4 } & & Baseline & $\begin{array}{l}\text { Follow-up after XBD173 } \\
\text { administration }\end{array}$ \\
\hline $\mathrm{A}$ & 954 & Clozapine $900 \mathrm{mg}+$ aripiprazol $5 \mathrm{mg}$ & Clozapine $900 \mathrm{mg}$ \\
$\mathrm{B}$ & 943 & Clozapine $500 \mathrm{mg}$ & Clozapine $500 \mathrm{mg}$ \\
$\mathrm{C}$ & 727 & Olanzapine $20 \mathrm{mg}$ & Olanzapine $15 \mathrm{mg}$ \\
$\mathrm{D}$ & 790 & Clozapine $350 \mathrm{mg}$ & Clozapine $300 \mathrm{mg}$ \\
$\mathrm{E}$ & 882 & Amisulpride $200 \mathrm{mg}$ & Olanzapine $10 \mathrm{mg}$ \\
$\mathrm{F}$ & 6 & Unmedicated & Unmedicated \\
$\mathrm{G}$ & 901 & Olanzapine $10 \mathrm{mg}$ & Risperidone 3 mg \\
\hline
\end{tabular}

group average of $0.47(N=7,95 \% \mathrm{CI}: 0.17$ to 0.78$)$, while the $V_{\mathrm{ND}}$ constrained to be equal for all the patients $(N=7$, all subjects included) was 0.68 corresponding to a mean occupancy of $92 \% \pm 15 \%$ (Fig. 2B). Despite the difference of $V_{\mathrm{T}}$ estimates, the two models (2TCM and $2 \mathrm{TCM} 1 \mathrm{~K})$ returned a similar fraction of specific binding $\left(V_{\mathrm{S}} / V_{\mathrm{T}}\right)$, corresponding to $58 \% \pm 10 \%$ for $2 \mathrm{TCM}$ and to $68 \% \pm 13 \%$ for $2 \mathrm{TCM} 1 \mathrm{~K}\left(V_{\mathrm{ND}}\right.$ fixed to population values).

\section{Simultaneous estimatation vs blocking study}

When we used SIME to estimate non-displaceable binding, individual $V_{\mathrm{ND}}$ estimates (mean $\pm \mathrm{sd}: 1.16 \pm 0.28 \mathrm{~mL} / \mathrm{cm}^{3}$ ) were significantly different than the corresponding one obtained with Lassen plot (mean $\pm \mathrm{sd}$ : $2.65 \pm 1.64 \mathrm{~mL} / \mathrm{cm}^{3}$; paired $t$-test $p: 0.045)$. On average, the SIME $V_{\mathrm{ND}}$ estimates were $45 \% \pm$ $22 \%$ lower than those obtained from the blocking studies (Table 3). This mismatched between SIME and Lassen plot estimates has been already shown by Schain and colleagues [35], who reported similar $V_{\mathrm{ND}}$ values for both healthy controls (mean \pm sd: $1.45 \pm 0.56 \mathrm{~mL} / \mathrm{cm}^{3}$ ) and Alzheimer disease patients $\left(\right.$ mean \pm sd: $\left.1.36 \pm 0.40 \mathrm{~mL} / \mathrm{cm}^{3}\right)$. In a recent study, comparing SIME $V_{\mathrm{ND}}$ estimates across different populations, Laurell and colleagues found a mean value of $1.12 \mathrm{~mL} / \mathrm{cm}^{3}$ for a group of 6 HABs first-episode psychosis patients, very well aligned with the SIME $V_{\mathrm{ND}}$ estimate obtained in our sample [25].

\section{Discussion}

To our knowledge, this is the first PET study to pharmacologically estimate the non-displaceable binding component $\left(V_{\mathrm{ND}}\right)$ in patients with schizophrenia. We find that the $V_{\mathrm{ND}}$ of $\left[{ }^{11} \mathrm{C}\right] \mathrm{PBR} 28$ in schizophrenia to be $1.99 \mathrm{~mL} / \mathrm{cm}^{3}$, a value that is very similar to the one previously reported for healthy controls $\left(1.98 \mathrm{~mL} / \mathrm{cm}^{3}\right)$ [31]. We also find that a substantial component of the $\left[{ }^{11} \mathrm{C}\right] \mathrm{PBR} 28 \mathrm{PET}$ signal is displaced by XBD173 in schizophrenia, indicating specific binding to TSPO.

Before we discuss the implications of this finding, we should address the potential limitations of this study. First, only one patient included in this study was unmedicated, with the remaining patients medicated with antipsychotic medication. The relationship between antipsychotic exposure and expression levels of the translocator protein (TSPO) remains unclear, although a rat study found no effect of antipsychotics on PBR28 (Bloomfield et al. 2018). Second, we have only scanned patients who were high affinity binders for TSPO. Therefore, in order for our results to be generalized, we need to assume that $V_{\mathrm{ND}}$ is consistent across binding affinity groups. Importantly, genotype polymorphisms are supposed to only affect the affinity of the tracer to TSPO, and therefore no differences in $V_{\mathrm{ND}}$ are thought to exist between genotype groups. This is supported by in vitro data using 3H-PBR28, which showed that $V_{\mathrm{ND}}$ does not differ across binding affinity class [30]. However, some data suggest that there may be a higher
Fig. 1 [11C]PBR28 brain PET tissue uptake (quantified with SUV) before (A) and after XBD173 administration (B). Images taken from scans of the same representative patient to show the effect of XBD173 on tracer uptake across the brain

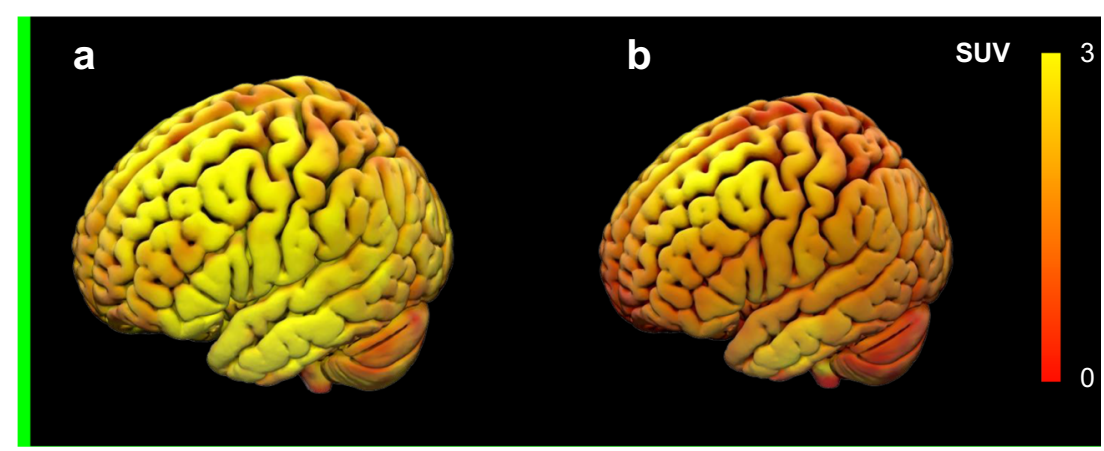


Table 2 Volumes of distribution $\left(V_{\mathrm{T}}\right)$ in different brain regions at baseline and after XBD173 administration

\begin{tabular}{|c|c|c|c|c|c|c|}
\hline \multirow[t]{3}{*}{ ROI } & \multicolumn{3}{|c|}{ Standard 2TCM } & \multicolumn{3}{|l|}{ 2TCM1K } \\
\hline & $\begin{array}{l}\text { Baseline } V_{\mathrm{T}} \\
\left(\mathrm{mL} / \mathrm{cm}^{3}\right)\end{array}$ & $\begin{array}{l}\text { Post-XBD173 } \\
V_{\mathrm{T}}\left(\mathrm{mL} / \mathrm{cm}^{3}\right)\end{array}$ & \multirow{2}{*}{$\begin{array}{l}\left(V_{\mathrm{T}}\right) \\
\text { change* } \\
(\%)\end{array}$} & $\begin{array}{l}\text { Baseline } V_{\mathrm{T}} \\
\left(\mathrm{mL} / \mathrm{cm}^{3}\right)\end{array}$ & $\begin{array}{l}\text { Post-XBD173 } \\
V_{\mathrm{T}}\left(\mathrm{mL} / \mathrm{cm}^{3}\right)\end{array}$ & \multirow{2}{*}{$\begin{array}{l}\left(V_{\mathrm{T}}\right) \\
\text { change* } \\
(\%)\end{array}$} \\
\hline & Mean \pm SD & Mean \pm SD & & Mean \pm SD & Mean $\pm \mathrm{SD}$ & \\
\hline Whole brain & $4.72 \pm 1.18$ & $2.16 \pm 1.05$ & $54 \%$ & $2.31 \pm 0.63$ & $0.70 \pm 0.26$ & $70 \%$ \\
\hline White matter & $4.30 \pm 0.95$ & $1.97 \pm 0.58$ & $54 \%$ & $1.34 \pm 0.38$ & $0.62 \pm 0.10$ & $54 \%$ \\
\hline Gray matter & $4.95 \pm 1.26$ & $2.45 \pm 1.62$ & $50 \%$ & $2.64 \pm 0.71$ & $0.76 \pm 0.34$ & $71 \%$ \\
\hline Occipital lobe & $4.76 \pm 1.26$ & $2.91 \pm 2.36$ & $39 \%$ & $2.56 \pm 0.73$ & $0.70 \pm 0.31$ & $73 \%$ \\
\hline $\begin{array}{l}\text { Temporal } \\
\text { lobe }\end{array}$ & $4.82 \pm 1.16$ & $2.06 \pm 0.85$ & $57 \%$ & $2.43 \pm 0.75$ & $0.73 \pm 0.29$ & $70 \%$ \\
\hline Frontal lobe & $4.81 \pm 1.21$ & $2.43 \pm 1.57$ & $49 \%$ & $2.49 \pm 0.65$ & $0.73 \pm 0.30$ & $71 \%$ \\
\hline Parietal lobe & $4.64 \pm 1.18$ & $2.91 \pm 2.65$ & $37 \%$ & $2.42 \pm 0.67$ & $0.71 \pm 0.31$ & $71 \%$ \\
\hline Amygdala & $6.67 \pm 2.09$ & $1.62 \pm 0.53$ & $76 \%$ & $2.49 \pm 1.55$ & $1.14 \pm 0.22$ & $54 \%$ \\
\hline Hippocampus & $5.25 \pm 1.23$ & $1.88 \pm 0.51$ & $64 \%$ & $2.59 \pm 1.07$ & $1.04 \pm 0.35$ & $60 \%$ \\
\hline Thalamus & $5.70 \pm 1.28$ & $1.79 \pm 0.45$ & $69 \%$ & $2.45 \pm 0.78$ & $0.90 \pm 0.29$ & $63 \%$ \\
\hline Striatum & $4.83 \pm 1.01$ & $1.86 \pm 0.60$ & $61 \%$ & $2.62 \pm 1.03$ & $0.74 \pm 0.18$ & $72 \%$ \\
\hline Cerebellum & $4.87 \pm 1.25$ & $2.27 \pm 1.44$ & $53 \%$ & $2.71 \pm 0.65$ & $0.78 \pm 0.34$ & $71 \%$ \\
\hline
\end{tabular}

$* V_{\mathrm{T}}$ change is computed as the relative difference between mean baseline $V_{\mathrm{T}}$ and mean post-XBD173 $V_{\mathrm{T}}$ ratio of specific to non-displaceable binding in HABs compared with MABs [23, 31]. In a previous study using XBD173 to determine $V_{\mathrm{ND}}$ in healthy controls, $\mathrm{BP}_{\mathrm{ND}}$ was higher in HABs compared with MABs in all ROIs studied [31]. However, the authors used a polymorphism plot to calculate an independent population estimate of $V_{\mathrm{ND}}$ which produced very similar population $V_{\mathrm{ND}}$ estimates (1.89 to 2.00). Future studies should aim to independently determine if $V_{\mathrm{ND}}$ is different among different binding affinity subjects. Third, we scanned subjects separated by an average of almost 2-year interval. It has been suggested that TSPO expression may change during the course of the disorder, but a recent study using BP as an outcome measure showed no differences between at-risk mental state individuals, recent onset schizophrenia, and chronic schizophrenia [10]. Furthermore, one of our study participants had the baseline and follow-up PET scan with 1-week interval and there was no difference in $V_{\mathrm{T}}$ or $V_{\mathrm{ND}}$ between this patient and the remaining ones. Finally, some methodological considerations should be taken into account. The occupancy plot is a simple and very common method to compute the tracer displaceable binding but it is not without limitation [27, 36]. First of all, there are alternative formulations to calculate the fractional receptor availability in molecular imaging studies $[14,24]$. Moreover, the occupancy plot is based on ordinary least squares that assumes noise-free independent variables and no autocorrelated measurement error. But this is not necessarily the case for the occupancy plot variables (both baseline $V_{\mathrm{T}}$ and delta $V_{\mathrm{T}}$ are noisy measures and regional estimates tend to be correlated with each other) and both the noise level and the variability of measurements can change depending on the radioligand and its target as well as on the set of ROIs used for the regression. Alternative estimation methods, which take into account noise on both axes, may be considered (e.g., likelihood estimation [28] or orthogonal regression) [42]). These methods, similarly to weighted estimation approaches, necessitate assumptions about the noise distributions of the measurements. To compare the results of this work with existent literature, we consistently use the same approach reported by other occupancy studies with PBR28 PET and XBD173. However, further investigations are needed to test the sensitivity of PBR28 $V_{\mathrm{ND}}$ estimates to the quantification methodology. Also the use of individual $V_{\mathrm{ND}}$ estimates requires further consideration. The individual $V_{\mathrm{ND}}$ estimates obtained for our subjects ranged between 1.50 and 5.55 for $2 \mathrm{TMC}$, between 0.14 and 1.03 for $2 \mathrm{TMC} 1 \mathrm{~K}$, and between 0.71 and 1.24 for the SIME method. From this data alone, it is not possible to ascertain whether the inter-subject variability represents true biological variability or is simply a consequence of the increased noise obtained from unconstrained fits. On the contrary, constraining the $V_{\mathrm{ND}}$ of all the subjects to the same population value is a very strong assumption, which opportunistically has the advantage of reducing the inter-subject variability. However, irrespective of the quantification method used, the reduction of tracer binding after XBD173 administration was global, supporting the idea TSPO is obviously distributed and that no brain region could be used as a true reference region with no or negligible tracer-specific binding. This implies to control for the variation of tracer-specific signal when a particular region is used as normative (or pseudo reference) region for the quantification of tracer binding across different groups of participants or before and after interventions that could modify brain TSPO expression [1]. 
Fig. 2 Occupancy plot to determine group mean $\left[{ }^{11} \mathrm{C}\right] \mathrm{PBR} 28 V_{\mathrm{ND}}$ with $2 \mathrm{TCM}(\mathrm{A})$ and $2 \mathrm{TCM} 1 \mathrm{~K}$ (B). Each point represents an individual subject ROI value. $V_{\mathrm{ND}}$ is constrained to be equal for all patients ( $N=7$, all subjects included). Note that the first subject on the list (ID = \#305, full circles) is the one that has been identified as the outlier in the individual $V_{\mathrm{ND}}$ analysis

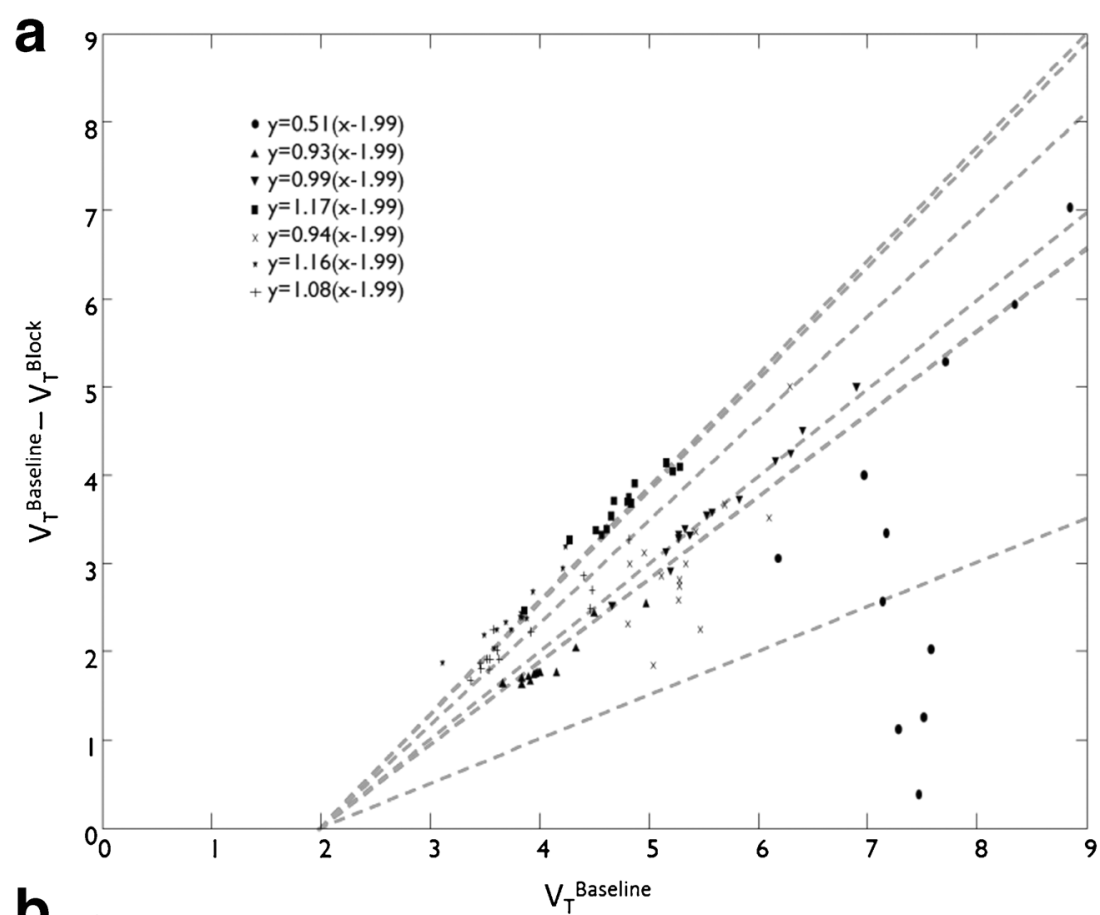

b

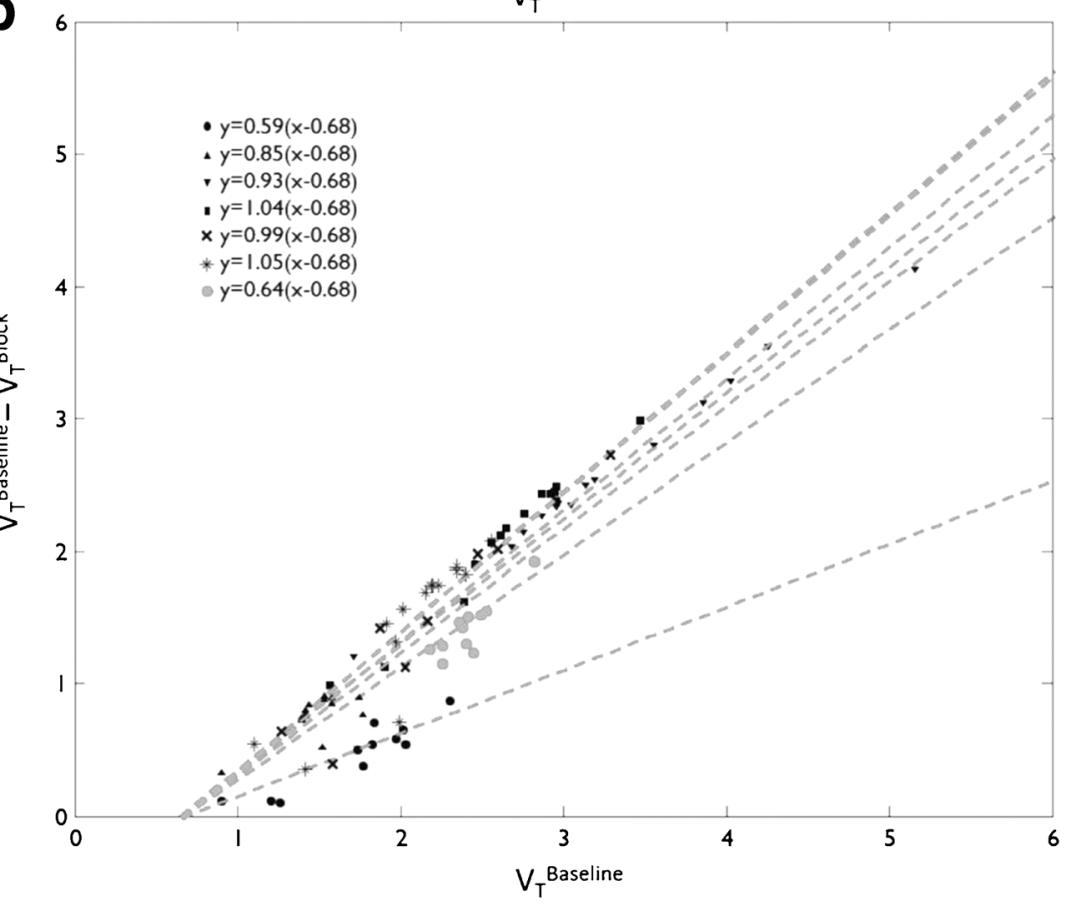

Our finding that $V_{\mathrm{ND}}$ is not altered in schizophrenia has implications for the interpretation of TSPO PET studies in schizophrenia. It shows that differences between groups are unlikely to be due to differences in $V_{\mathrm{ND}}$, indicating that where $V_{\mathrm{T}}$ differences are reported they most likely represent alterations in specific binding in blood or brain. It also indicates that lower non-specific binding does not explain the discrepant findings between studies reporting $\mathrm{BP}_{\mathrm{ND}}$ and those reporting $V_{\mathrm{T}}$ ([26]; Plavén-Sigray $\mathrm{P}$ et al., 2018). The XBD173 binds to the translocator protein $(18 \mathrm{kDa})$ with nanomolar affinity and shows negligible affinity to a broad range of neurotransmitter receptors (Kita et al., 2004) and our finding indicates a large component of PET signal in schizophrenia is therefore specific binding to TSPO.

\section{Conclusions}

In conclusion, we have used a pharmacological blockade of TSPO with XBD173 to calculate a population level 
Table 3 Individual $V_{\mathrm{ND}}$ estimates with SIME method and with Lassen plot after XBD173 blocking

Standard 2TCM modeling

2TCM1K modeling

\begin{tabular}{lllll}
\cline { 2 - 4 } Subject ID & $\begin{array}{l}\text { SIME } V_{\mathrm{ND}} \text { from } \\
\text { baseline scan }\left(\mathrm{mL} / \mathrm{cm}^{3}\right)\end{array}$ & $\begin{array}{l}\text { Lassend plot } V_{\mathrm{ND}} \\
\left(\mathrm{mL} / \mathrm{cm}^{3}\right)[95 \% \mathrm{CI}]\end{array}$ & $\begin{array}{l}\text { Rel Dif }(\%) \\
\text { Lassend plot } V_{\mathrm{ND}} \\
\left(\mathrm{mL} / \mathrm{cm}^{3}\right)[95 \% \mathrm{CI}]\end{array}$ \\
\hline$\# 305$ & 1.24 & $5.55[4.46,6.43]$ & $-78 \%$ & $0.14[0.11,0.16]$ \\
$\# 314$ & 0.94 & $3.05[2.45,3.53]$ & $-69 \%$ & $0.78[0.63,0.91]$ \\
$\# 316$ & 1.68 & $2.31[1.86,2.67]$ & $-27 \%$ & $1.03[0.83,1.19]$ \\
$\# 337$ & 1.14 & $1.51[1.17,1.78]$ & $-24 \%$ & $0.27[0.21,0.32]$ \\
$\# 339$ & 1.17 & $2.09[1.68,2.41]$ & $-44 \%$ & $1.01[0.81,1.16]$ \\
$\# 378$ & 0.71 & $1.67[1.34,1.94]$ & $-58 \%$ & $0.89[0.71,1.03]$ \\
\hline
\end{tabular}

$\left[{ }^{11} \mathrm{C}\right] \mathrm{PBR} 28 V_{\mathrm{ND}}$. Our results show a substantial component of the $\left[{ }^{11} \mathrm{C}\right] \mathrm{PBR} 28$ signal is specific binding to TSPO specific in schizophrenia patients and that the $V_{\mathrm{ND}}$ in patients with schizophrenia is similar to that previously reported in healthy controls, indicating that altered non-specific binding does not account for discrepant PET findings in schizophrenia.

Supplementary Information The online version contains supplementary material available at https://doi.org/10.1007/s00259-021-05327-x.

Funding Open access funding provided by Imperial College London. This study was funded by grants MC-A656-5QD30 from the Medical Research Council-UK, 666 from the Maudsley Charity 094849/Z/10/Z from the Brain and Behavior Research Foundation, and Wellcome Trust to Dr. Howes.

\section{Declarations}

Ethical approval All procedures performed in studies involving human participants were in accordance with the ethical standards of the institutional and/or national research committee and with the 1964 Helsinki declaration and its later amendments or comparable ethical standards.

Conflict of interest Dr. Reis Marques conducts research funded by the Medical Research Council (UK) and King's College London. Dr. Reis Marques has received honoraria for speaking and chairing engagements from Lundbeck, Janssen, and Astellas. Dr. Veronese has received honoraria from GSK. Prof Howes conducts research funded by the Medical Research Council (UK), the National Institute of Health Research (UK), and the Maudsley Charity. Prof Howes has received investigator-initiated research funding from and/or participated in advisory/speaker meetings organized by Astra-Zeneca, BMS, Eli Lilly, Jansenn, Lundbeck, Lyden-Delta, Servier, and Roche. Neither Prof Howes nor his family have been employed by or have holdings/a financial stake in any biomedical company. E.A.R. is a consultant for Opiant Pharmaceutical, AbbVie, and Teva, and a shareholder in GSK. GES and AS are employees of Invicro. Dr. Owen reports no financial relationships with commercial interests.

Open Access This article is licensed under a Creative Commons Attribution 4.0 International License, which permits use, sharing, adaptation, distribution and reproduction in any medium or format, as long as you give appropriate credit to the original author(s) and the source, provide a link to the Creative Commons licence, and indicate if changes were made. The images or other third party material in this article are included in the article's Creative Commons licence, unless indicated otherwise in a credit line to the material. If material is not included in the article's Creative Commons licence and your intended use is not permitted by statutory regulation or exceeds the permitted use, you will need to obtain permission directly from the copyright holder. To view a copy of this licence, visit http://creativecommons.org/licenses/by/4.0/.

\section{References}

1. Albrecht DS, Normandin MD, Shcherbinin S, Wooten DW, Schwarz AJ, Zürcher NR, et al. Pseudoreference regions for glial imaging with ${ }^{11} \mathrm{C}-\mathrm{PBR} 28$ : investigation in 2 clinical cohorts. J Nucl Med. 2018;59(1):107-14.

2. Bloomfield PS, Selvaraj S, Veronese M, Rizzo G, Bertoldo A, Owen DR, et al. Microglial activity in people at ultra high risk of psychosis and in schizophrenia: an [(11)C]PBR28 PET brain imaging study. Am J Psychiatry. 2016;173(1):44-52.

3. Collste K, Forsberg A, Varrone A, Amini N, Aeinehband S, Yakushev I, et al. Test-retest reproducibility of [(11)C]PBR28 binding to TSPO in healthy control subjects. Eur J Nucl Med Mol Imaging. 2016;43(1):173-83.

4. Collste K, Plavén-Sigray P, Fatouros-Bergman H, Victorsson P, Schain M, Forsberg A, Amini N, Aeinehband S. Karolinska Schizophrenia Project (KaSP) consortium, Erhardt S, Halldin C, Flyckt L, Farde L, Cervenka S. Lower levels of the glial cell marker TSPO in drug-naive first-episode psychosis patients as measured using PET and [11C]PBR28. Mol Psychiatry. 2017;22(6):850-856

5. Conen S, Gregory CJ, Hinz R, Smallman R, Corsi-Zuelli F, Deakin B, Talbot PS. Neuroinflammation as measured by positron emission tomography in patients with recent onset and established schizophrenia: implications for immune pathogenesis. Mol Psychiatry 2020.

6. Cosenza-Nashat M, Zhao ML, Suh HS, Morgan J, Natividad R, Morgello S, Lee SC. Expression of the translocator protein of $18 \mathrm{kDa}$ by microglia, macrophages and astrocytes based on immunohistochemical localization in abnormal human brain. Neuropathol Appl Neurobiol. 2009;35(3):306-28.

7. Coughlin JM, Wang Y, Ma S, Yue C, Kim PK, Adams AV, et al. Regional brain distribution of translocator protein using [(11)C]DPA-713 PET in individuals infected with HIV. J NeuroOncol. 2014;20(3):219-32.

8. Cunningham VJ, Rabiner EA, Slifstein M, Laruelle M, Gunn RN Measuring drug occupancy in the absence of a reference region: the 
Lassen plot re-visited. J Cereb Blood Flow Metab. 2010;30(1):4650.

9. De Picker L, Ottoy J, Verhaeghe J, Deleye S, Wyffels L, Fransen E, et al. State-associated changes in longitudinal $\left[{ }^{18} \mathrm{~F}\right]-\mathrm{PBR} 111 \mathrm{TSPO}$ PET imaging of psychosis patients: evidence for the accelerated ageing hypothesis? Brain Behav Immun. 2019;77:46-54.

10. Di Biase MA, Zalesky A, O'keefe G, Laskaris L, Baune BT, Weickert CS, Olver J, McGorry PD, Amminger GP, Nelson B, Scott AM, Hickie I, Banati R, Turkheimer F, Yaqub M, Everall IP, Pantelis C, Cropley V. PET imaging of putative microglial activation in individuals at ultra-high risk for psychosis, recently diagnosed and chronically ill with schizophrenia. Transl Psychiatry. 2017;7(8):e1225.

11. Doorduin J, de Vries EF, Willemsen AT, de Groot JC, Dierckx RA, Klein HC. Neuroinflammation in schizophrenia-related psychosis: a PET study. J Nucl Med. 2009;50(11):1801-7.

12. Edison P, Brooks DJ, Turkheimer FE, Archer HA, Hinz R. Strategies for the generation of parametric images of [11C]PIB with plasma input functions considering discriminations and reproducibility. Neuroimage. 2009;48(2):329-38.

13. First, M., Spitzer, R., Miriam, G., \& Williams, J. Structured clinical interview of DSM-IV-TR AXIS I disorders-patient edition (SCID-I/ P, 1/2007 revision). (Biometrics research, 2007).

14. Gjedde A, Wong DF. Receptor occupancy in absence of reference region. Neuroimage. 2000;11:S48.

15. Hafizi S, Tseng HH, Rao N, Selvanathan T, Kenk M, Bazinet RP, Suridjan I, Wilson AA, Meyer JH, Remington G, Houle S, Rusjan PM, Mizrahi R. Imaging Microglial Activation in Untreated FirstEpisode Psychosis: A PET Study With [18F]FEPPA. Am J Psychiatry. 2017;174(2):118-24.

16. Holmes SE, Hinz R, Drake RJ, Gregory CJ, Conen S, Matthews JC, Anton-Rodriguez JM, Gerhard A, Talbot PS. In vivo imaging of brain microglial activity in antipsychotic-free and medicated schizophrenia: a [11C](R)-PK11195 positron emission tomography study. Mol Psychiatry. 2016 Dec;21(12):1672-1679.

17. Howes OD, McCutcheon R. Inflammation and the neural diathesisstress hypothesis of schizophrenia: a reconceptualization. Transl Psychiatry. 2017;7(2):e1024 Review.

18. Howes OD, Murray RM. Schizophrenia: an integrated sociodevelopmental-cognitive model. Lancet. 2014;383(9929): 1677-87 Review.

19. Ikawa M, Lohith TG, Shrestha S, Telu S, Zoghbi SS, Castellano S, et al. 11C-ER176, a radioligand for 18-kDa translocator protein, has adequate sensitivity to robustly image all three affinity genotypes in human brain. J Nucl Med. 2017;58:320-5.

20. Innis RB, Cunningham VJ, Delforge J, Fujita M, Gjedde A, Gunn RN, et al. J Cereb Blood Flow Metab. 2007;27(9):1533-9 Review.

21. Kay SR, Fiszbein A, Opler LA. The positive and negative syndrome scale (PANSS) for schizophrenia. Schizophr Bull. 1987;13(2):261-76.

22. Kobayashi M, Jiang T, Telu S, Zoghbi SS, Gunn RN, Rabiner EA, et al. ${ }^{11} \mathrm{C}$-DPA-713 has much greater specific binding to translocator protein $18 \mathrm{kDa}$ (TSPO) in human brain than does ${ }^{11} \mathrm{C}-(R)-\mathrm{PK} 11195 . \mathrm{J}$ Cereb Blood Flow Metab. 2018 Mar;38(3):393-403

23. Kreisl WC, Jenko KJ, Hines CS, Lyoo CH, Corona W, Morse CL, et al. Biomarkers Consortium PET Radioligand Project Team. A genetic polymorphism for translocator protein $18 \mathrm{kDa}$ affects both in vitro and in vivo radioligand binding in human brain to this putative biomarker of neuroinflammation. J Cereb Blood Flow Metab. 2013;33(1):53-8.

24. Lassen NA, Bartenstein PA, Lammertsma AA, Prevett MC, Turton DR, Luthra SK, et al. Benzodiazepine receptor quantification in vivo in humans using [11C]flumazenil and PET: application of the steadystate principle. J Cereb Blood Flow Metab. 1995;15(1):152-65.

25. Laurell GL, Plavén-Sigray P, Jucaite A, Varrone A, Cosgrove KP, Svarer C, Knudsen GM, Ogden RT, Zanderigo F, Cervenka S, Hillmer AT, Schain M. Non-displaceable binding is a potential confounding factor in 11CPBR28 TSPO PET studies. J Nucl Med. 2020 jnumed.120.243717.

26. Marques TR, Ashok AH, Pillinger T, Veronese M, Turkheimer FE, Dazzan P, et al. Neuroinflammation in schizophrenia: meta-analysis of in vivo microglial imaging studies. Psychol Med. 2018;25:1-11.

27. Naganawa M, Gallezot JD, Rossano S, Carson RE. Quantitative PET imaging in drug development: estimation of target occupancy. Bull Math Biol. 2019;81(9):3508-41. https://doi.org/10.1007/ s11538-017-0374-2.

28. Ogden RT. Estimation of kinetic parameters in graphical analysis of PET imaging data. Stat Med. 2003;22(22):3557-68.

29. Ottoy J, De Picker L, Verhaeghe J, Deleye S, Wyffels L, Kosten L, et al. Staelens S. 18F-PBR111 PET imaging in healthy controls and schizophrenia: test-retest reproducibility and quantification of neuroinflammation. J Nucl Med. 2018;59(8):1267-74.

30. Owen DR, Lewis AJ, Reynolds R, Rupprecht R, Eser D, Wilkins $\mathrm{MR}$, et al. Variation in binding affinity of the novel anxiolytic XBD173 for the $18 \mathrm{kDa}$ translocator protein in human brain. Synapse. 2011;65:257-9.

31. Owen DR, Guo Q, Kalk NJ, Colasanti A, Kalogiannopoulou D, Dimber R, et al. Determination of [(11)C]PBR28 binding potential in vivo: a first human TSPO blocking study. J Cereb Blood Flow Metab. 2014;34(6):989-94.

32. Plavén-Sigray P, Matheson GJ, Collste K, Ashok AH, Coughlin JM, Howes OD, et al. Positron emission tomography studies of the glial cell marker translocator protein in patients with psychosis: a meta-analysis using individual participant data. Biol Psychiatry. 2018;84(6):433-42.

33. Plavén-Sigray P, Schain M, Zanderigo F, Karolinska. [(11)C]PBR28 study group, Rabiner EA, Gunn RN, Ogden RT, Cervenka S. Accuracy and reliability of $\left[{ }^{11} \mathrm{C}\right] \mathrm{PBR} 28$ specific binding estimated without the use of a reference region. Neuroimage. 2019;188:102-10.

34. Rizzo G, Veronese M, Heckemann RA, Selvaraj S, Howes OD, Hammers A, et al. The predictive power of brain mRNA mappings for in vivo protein density: a positron emission tomography correlation study. J Cereb Blood Flow Metab. 2014;34(5):827-35.

35. Schain M, Zanderigo F, Ogden RT, Kreisl WC. Non-invasive estimation of $\left[{ }^{11}\right.$ C]PBR28 binding potential. Neuroimage. 2018;169:278-85.

36. Slifstein M, Laruelle M. Effects of statistical noise on graphic analysis of PET neuroreceptor studies. J Nucl Med. 2000;41(12):2083-8.

37. Takano A, Arakawa R, Ito H, Tateno A, Takahashi H, Matsumoto R, Okubo Y, Suhara T. Peripheral benzodiazepine receptors in patients with chronic schizophrenia: a PET study with [11C]DAA1106. Int J Neuropsychopharmacol. 2010 Aug;13(7): 943-50.

38. Todd Ogden R, Zanderigo F, Parsey RV. Estimation of in vivo nonspecific binding in positron emission tomography studies without requiring a reference region. Neuroimage. 2015;108:234-42.

39. Tonietto M, Veronese M, Rizzo G, Zanotti-Fregonara P, Lohith TG, Fujita M, et al. Improved models for plasma radiometabolite correction and their impact on kinetic quantification in PET studies. J Cereb Blood Flow Metab. 2015;35(9):1462-9.

40. Van Berckel BN, Bossong MG, Boellaard R, Kloet R, Schuitemaker A, Caspers E, et al. Microglia activation in recentonset schizophrenia: a quantitative (R)-[11C]PK11195 positron emission tomography study. Biol Psychiatry. 2008;64(9):820-2. 
41. Van der Doef TF, de Witte LD, Sutterland AL, Jobse E, Yaqub M, Boellaard R, et al. In vivo (R)-[(11)C]PK11195 PET imaging of $18 \mathrm{kDa}$ translocator protein in recent onset psychosis. NPJ Schizophr. 2016;2:16031.

42. Varga J, Szabo Z. Modified regression model for the Logan plot. J Cereb Blood Flow Metab. 2002;22(2):240-4.

43. Veronese M, Reis Marques T, Bloomfield PS, Rizzo G, Singh N, Jones D, et al. Kinetic modelling of [11C]PBR28 for $18 \mathrm{kDa}$ translocator protein PET data: a validation study of vascular modelling in the brain using XBD173 and tissue analysis. J Cereb Blood Flow Metab. 2018;38(7):1227-42.

Publisher's note Springer Nature remains neutral with regard to jurisdictional claims in published maps and institutional affiliations. 